\title{
Importance-Performance Analysis of Mountain Village Promotion Projects in the Forest Sector by Upper-Level Local Governments
}

\author{
Byung-Hoon Kang, Seong-Hak Kim*, and Jin-Hae Chae \\ Researcher, Division of Forest Human Services Research, National Institute of Forest Science, 57, Hoegi-ro, Dongdaemun-gu, Seoul \\ 02455, Republic of Korea
}

ABSTRACT

Background and objective: Due to the recent crisis of extinction in local areas, the mountain village promotion policy is recognized as an important task. This study examined the priorities of major policy projects in the forest sector that affect mountain village promotion.

Methods: For research methods, literature search, expert advisory meetings, and a survey were conducted. The survey was conducted on 42 policy stakeholders from June 1 to August 13, 2021. The literature search was based on policy projects in the forest sector by 8 upper-level local governments including mountain villages. For questionnaire items, 173 forest policy projects were classified into 27 types through expert review, and the importance and performance of each type were rated on a 5-point Likert scale. Paired t-test, IPA, Locus for Focus model, and Borich needs assessment were used as the analysis methods, and the statistical program SPSS 21.0 was used as the analytical tool.

Results: The results showed that 'creating forest-related jobs' and 'supporting cultivation of professional forestry workers' both showed high importance and performance, implying that they would show an effect in mountain village promotion. 'Creating forests for environmental improvement', 'discovering forest cultural assets' 'establishing and boosting forest tourism', 'providing forest therapy services', 'creating forest-related jobs', 'supporting community revitalization', and 'urban-rural exchanges' were found to be the types that needed improvement and concentration for mountain village promotion. In particular, 'creating forests for environmental improvement' and 'discovering forest cultural assets' were derived as priority considerations for mountain village promotion policies.

Conclusion: In summary, it was found that in order to promote mountain villages, various content projects must be improved and carried out to enhance the physical environment and revitalize mountain villages.

Keywords: forest policy, IPA, order of priority, environmental improvement, forest culture

\section{Introduction}

As Korea has entered the aging society, the population of mountain villages that are classified as less favored areas shows a greater decline than rural villages. The population of forestry households in mountain villages announced by Korea Forest Service in 2020 decreased by $17.85 \%$ from 217,197 in 2015 to 178,419 in 2019 , and the population inflow into mountain villages also decreased from 69,244 in 2015 to 57,478 in 2019 (Korea Forest Service, 2020). Forecasts about local extinction that is recently rising as an issue show that, due to not only natural but also social factors, there are more mountain villages with high risk of extinction (72.9\%) than rural villages (49.2\%) in 2018 (National Institute of Forest Science [NIFoS], 2019). As such, mountain villages that take up $43.6 \%$ of all land area are distributed throughout an extensive part of the national territory, but they are constantly excluded from policy beneficiaries since they are underpopulated (NIFoS, 2020).

Korea Forest Service established the mountain village promotion policy for balanced national development and has carried forward policy projects creating and designating

Received: September 30, 2021, Revised: October 22, 2021, Accepted: November 2, 2021

First author: Byung-Hoon Kang, byunghoon21@korea.kr, (1) https://orcid.org/0000-0002-0207-4885

*Corresponding author: Seong-Hak Kim, ksh0615@korea.kr, (D) https://orcid.org/0000-0002-0847-6471 
about 360 mountain villages as of 2018, starting with the mountain ecological village project in 1995 until the recent forest healing village project. The mountain village promotion policy was implemented with the goal of improving the living environment for local residents, supporting their income, and utilizing and expanding forest resources. The policy seeks change in its implementation method towards region-led and resident-focused method, along with the expansion of spatial functions of mountain villages according to the local conditions. The recent decentralization is activating the region-led policy at the level of upper-level local governments, but due to poor financial independence of local governments, the mountain village project is pushed to the back burner, thereby showing limitations in implementation (NIFoS, 2021a). Thus, to determine the current state and solve problems in activating the mountain village policy project, the National Institute of Forest Science has closely investigated human resources, regional resources, base resources, and forest resources to quantitatively and qualitatively provide implications of the region-led project (NIFoS, 2021b). Despite the approach in terms of research, Korea Forest Service is facing difficulties in establishing the mountain village promotion policy since the transfer of local finances in 2020. Moreover, policy projects in the forest sector currently decided at the level of upper-level local governments are carried forward in terms of conserved use of resources, thereby lacking systematic approach to promote mountain villages. This can be a limitation in the selection process that determines the policy project based on the will of the policymaker without objective priorities.

To solve this problem, various analytical techniques are recently studied to set policy priorities and determine the effectiveness of the decentralization policy as a research approach (So et al., 2019; Seo and Hwang, 2019; Byun et al., 2019). According to previous studies, there was a difference in policy priorities between stakeholders of policy implementation and local residents (Park, 2017; So et al., 2019), and the results also varied depending on the analysis method used (Seo and Hwang, 2019). Reviewing policy priorities with various analysis methods is necessary to obtain objectivity and efficiency of region-led policies in the decentralized era. To develop and utilize projects in mountain village promotion with forest policies established by the upper-level local governments since decentralization, this study examines the importance and performance of policy projects using various analytical techniques and objectively investigates policy priorities.

\section{Research Methods}

\section{Research design}

This study was conducted to figure out the priorities of policy projects in the forest sector carried out by upper-level local governments. To this end, we collected policy projects in the forest sector carried out by 8 upper-level local governments and had them categorized by related experts based on bibliographic search and expert advisory meetings. The survey items were developed to rate importance and performance of the categorized policy projects on a 5-point scale, and the survey was conducted on policy stakeholders (public officers, experts, researchers). It was conducted by email for about 2 months from June 1 to August 13, 2021. The data collected were analyzed using paired t-test, Importance-Performance Analysis (IPA), Locus for Focus Model (LF model), and Borich needs assessment, and SPSS 21.0 was used for analysis (Fig. 1).

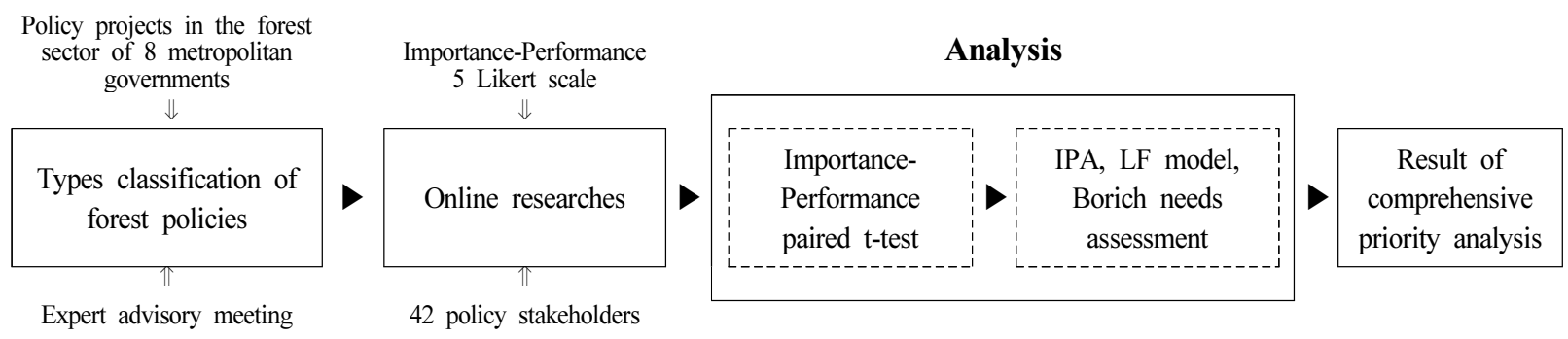

Fig. 1. Research design. 


\section{Questionnaire design}

To develop the survey items, we categorized the policy projects in the forest sector by upper-level local governments. For categorization, we collected the major policies and business plans in the forest sector by 8 upper-level local governments (Gyeonggi-do, Gangwon-do, Gyeongsangnam-do, Gyeongsangbuk -do, Jeollanam-do, Jeollabuk-do, Chungcheongnam-do, and Chungcheongbuk- do) including officially designated mountain villages. We analyzed them and came up with 173 policy projects that affect mountain village promotion among policy projects in the forest sector, classifying them into 5 categories based on review by 3 experts in local administration. With reference to related literatures, we classified the poli- cy projects into 27 types based on their characteristics and contents. The categorized policy projects are as follows: 6 types in boosting forestry ('supporting cultivation of professional forestry workers', 'creating a production base for forest products', 'strengthening competitiveness in clean forest products', 'local forestry cooperative activation project', 'Baekdudaegan resident support project', and 'nurturing the wood industry'), 6 types in creating green infrastructure ('creating forests for environmental improvement', 'creating green areas in living spaces', 'creating and managing street trees', 'creating dulle-gil (trails)', 'spreading and industrializing garden culture', 'creating nice hiking trails'), 6 types in providing forest welfare service ('creating and operating forest recreation facilities', 'boosting forest leisure and sports', 'strengthening

Table 1. Type classification of policy projects in the forest sector by 8 upper-level local governments in 2021

\begin{tabular}{|c|c|c|c|c|c|c|c|c|c|c|}
\hline \multirow{2}{*}{ No. } & \multirow{2}{*}{ Category } & \multirow{2}{*}{ Type } & \multicolumn{8}{|c|}{ Upper-level local government $^{z}$} \\
\hline & & & GG & GW & GN & GB & $\mathrm{JN}$ & JB & $\mathrm{CN}$ & $\mathrm{CB}$ \\
\hline 1 & \multirow{6}{*}{ Boosting forestry } & Supporting cultivation of professional forestry workers & $\circ$ & - & - & - & $\circ$ & - & - & - \\
\hline 2 & & Creating a production base for forest products & $\circ$ & $\circ$ & $\circ$ & $\circ$ & $\circ$ & $\circ$ & - & - \\
\hline 3 & & Strengthening competitiveness in clean forest products & $\circ$ & $\circ$ & - & $\circ$ & $\circ$ & - & - & $\circ$ \\
\hline 4 & & Local forestry cooperative activation project & - & - & $\circ$ & $\circ$ & - & - & - & - \\
\hline 5 & & Baekdudaegan resident support project & - & ० & - & $\circ$ & - & - & - & - \\
\hline 6 & & Nurturing the wood industry & $\circ$ & $\circ$ & - & - & - & - & - & $\circ$ \\
\hline 7 & \multirow{6}{*}{$\begin{array}{l}\text { Creating green } \\
\text { infrastructure }\end{array}$} & Creating forests for environmental improvement & $\circ$ & - & - & $\circ$ & $\circ$ & $\circ$ & $\circ$ & $\circ$ \\
\hline 8 & & Creating green areas in living spaces & - & - & $\circ$ & - & - & ○ & $\circ$ & - \\
\hline 9 & & Creating and managing street trees & - & ○ & - & - & $\circ$ & ० & - & - \\
\hline 10 & & Creating dulle-gil (trails) & ० & - & - & $\circ$ & $\circ$ & - & - & $\circ$ \\
\hline 11 & & Spreading and industrializing garden culture & - & ○ & - & $\circ$ & $\circ$ & - & - & $\circ$ \\
\hline 12 & & Creating nice hiking trails & $\circ$ & - & $\circ$ & - & $\circ$ & - & - & \\
\hline 13 & \multirow{6}{*}{$\begin{array}{l}\text { Providing forest } \\
\text { welfare service }\end{array}$} & Creating and operating forest recreation facilities & $\circ$ & $\circ$ & $\circ$ & $\circ$ & $\circ$ & - & - & - \\
\hline 14 & & Boosting forest leisure and sports & - & $\circ$ & $\circ$ & $\circ$ & $\circ$ & $\circ$ & $\circ$ & $\circ$ \\
\hline 15 & & Strengthening the base for forest education & - & $\circ$ & - & $\circ$ & $\circ$ & $\circ$ & - & $\circ$ \\
\hline 16 & & Providing forest therapy service & ○ & - & - & $\circ$ & $\circ$ & $\circ$ & - & - \\
\hline 17 & & Creating timber culture experience centers & - & $\circ$ & - & - & $\circ$ & - & - & - \\
\hline 18 & & Creating forest-related jobs & $\circ$ & $\circ$ & $\circ$ & $\circ$ & $\circ$ & $\circ$ & - & $\circ$ \\
\hline 19 & \multirow{6}{*}{$\begin{array}{l}\text { Creating a } \\
\text { regional base }\end{array}$} & Supporting community revitalization & - & o & - & - & $\circ$ & $\circ$ & - & $\circ$ \\
\hline 20 & & Establishing and boosting forest tourism & - & ० & - & $\circ$ & - & $\circ$ & $\circ$ & - \\
\hline 21 & & Income-based mountain village housing project & - & $\circ$ & - & - & - & - & - & - \\
\hline 22 & & Creating the base for development of the stone industry & ० & - & - & - & - & - & - & - \\
\hline 23 & & Establishing an integrated joint mountain monitoring system & ० & ○ & $\circ$ & $\circ$ & $\circ$ & ○ & $\circ$ & $\circ$ \\
\hline 24 & & Urban-rural exchange & - & $\circ$ & - & - & $\circ$ & ० & - & - \\
\hline 25 & \multirow{3}{*}{$\begin{array}{l}\text { Promoting forest } \\
\text { culture tourism }\end{array}$} & Discovering forest cultural assets & - & - & - & $\circ$ & $\circ$ & ० & - & - \\
\hline 26 & & Developing forest cultural assets into tourism resources & - & - & - & - & - & ० & - & $\circ$ \\
\hline 27 & & Holding forest expositions or fairs, etc. & - & $\circ$ & - & - & $\circ$ & $\circ$ & - & - \\
\hline
\end{tabular}

$z^{*}$ Reorganized based on the main business report for 2021 of each upper-level local government 


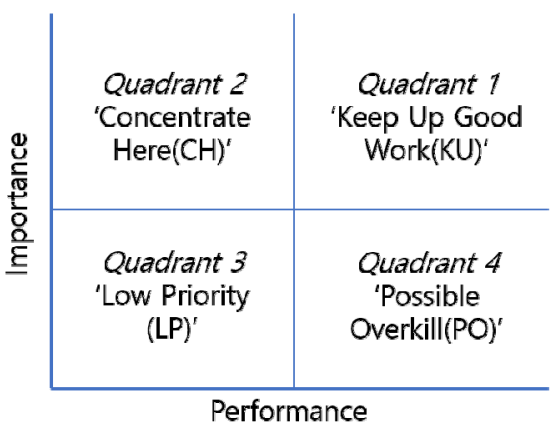

(a)

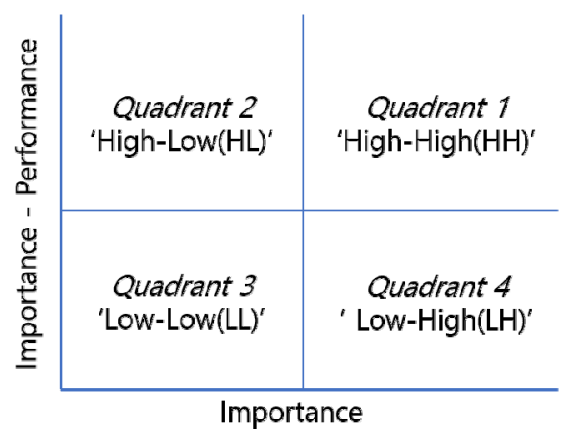

(b)

(c) Borich needs assessment formula $=\frac{\Sigma(R C L-P C L) \times \overline{R C L}}{N}$

Fig. 2. Priority analysis model: (a) IPA; (b) LF Model; (c) Borich needs assessment Fomula: $R C L$ (importance level), $P C L$ (performance level), $\overline{R C L}$ (average of Importance level), $\boldsymbol{N}$ (total number of cases).

the base for forest education', 'providing forest therapy service', 'creating timber culture experience centers', 'creating forest-related jobs'), 6 types in creating a regional base ('supporting community revitalization', 'establishing and boosting mountain tourism', 'income-based mountain village housing project', 'creating the base for development of the stone industry', 'establishing an integrated joint mountain monitoring system', and 'urban-rural exchange'), and 3 types in promoting forest culture tourism ('discovering forest cultural assets', 'developing forest cultural assets into tourism resources', and 'holding forest expositions or fairs, etc.') (Table 1). The survey items developed based on the above were comprised of 1) characteristics of respondents (occupation, length of service), 2) importance of 27 types rated on a 5-point scale, and 3) performance of 27 types rated on a 5-point scale. In this study, importance indicates the level of direct and indirect importance of the policy project in relation to boosting mountain villages, and performance indicates the level of how implementing the policy project will actually contribute to boosting mountain villages.

\section{Analysis Method}

\section{Priorities and needs analysis}

This study examined whether there is a significant difference between importance and performance of policy projects in the forest sector using a paired t-test and analyzed needs and priorities for comprehensive priority analysis of the projects. The tools used were paired t-test, ImportancePerformance Analysis (IPA), Locus for Focus Model (LF model), and Borich needs assessment (Fig. 2). Before priority analysis, we conducted a paired t-test and tested the significance to determine whether there is a significant difference between importance and performance of each type. The paired t-test has limitations in showing the characteristics of each item since it shows simple comparison among the items, which is why priority analysis was applied.

In priority analysis, IPA was developed by Martilla and James (1977) for performance analysis, and this is currently used to identify the priorities in matters that need improvement (Deng, 2007). The priorities are identified by putting importance on the $\mathrm{Y}$-axis and performance on the $\mathrm{X}$-axis in two dimensions to express the dispersion and divide the items into quadrants based on the mean. The priorities of each quadrant are in the order of Quadrant 2 'Concentrate here (CH)', Quadrant 1 'Keep up the good work (KU)', Quadrant 3 'Low priority (LP)', and Quadrant 4 'Possible overkill (PO)'. On the other hand, IPA cannot effectively identify the priorities if there is not enough difference between importance and performance or there are too many survey items (Yang and Chung, 2010). Moreover, since it measures both importance and performance at once, each item affects one another and thereby not independent, causing them to be concentrated in Quadrants 1 and $3(\mathrm{Oh}$, 
2001). Therefore, an additional analysis method must be implemented to identify the priorities.

The LF model (Mink et al., 1991) is an analysis method using discrepancy between importance and performance. It visualizes the priorities by putting discrepancy on the $\mathrm{Y}$-axis and importance on the $\mathrm{X}$-axis in two dimensions, dividing the items into quadrants based on the mean. The highest priority is Quadrant 1 'High-High $(\mathrm{HH})$ ', and the next priority may be either Quadrant 2 'High-Low (HL)' and Quadrant 4 'Low-High (LH)' depending on the researcher's intentions (Byun et al., 2019). Finally, Quadrant 3 'Low-Low (LL)' has the lowest priority. The LF model can clearly distinguish the priorities based on the means, but as limitations in that it cannot provide accurate values.

Borich needs assessment is a method developed by Borich (1980) that analyzes needs and derives priorities using discrepancy between importance and performance like the LF model. In Borich needs assessment, the priorities of needs are higher when importance is high and performance is low, and discrimination power among subjects increases by giving weights depending on the level of needs, showing higher priorities for higher needs (Oh et al., 2014). However, it is ambiguous how many ranks from the top should be considered among the analyzed priorities.

\section{Comprehensive priority analysis}

This study came up with comprehensive priorities based on IPA, LF model, and Borich needs assessment. These three methods all analyze the priorities of the subjects, but each has its limitations. Therefore, we used the method that mixes all three methods to overcome the limitations. This mixed analysis method is used mostly to set the priorities for educational needs and improvements in education, and its validity is proved by previous studies (Kang et al., 2021; Ha and Park, 2021; Chae et al., 2021; Seo et al., 2016).
We selected the types that are among the top priorities in Borich need assessment that are also included in Quadrant 1 or Quadrant 2 in IPA and the LF model as the comprehensive priority types. Here, the top priorities in Borich needs assessment are those with high needs up to the number of types included in HH in the LF model among the results of Borich needs assessment according to the method presented by Cho (2009) (Park and Lee, 2016; Yang et al., 2015; Lee et al., 2020; Lee and Jung, 2021).

\section{Results and Discussion}

\section{Characteristics of respondents}

There were total 42 respondents, such as public officers 25 public officers $(59.52 \%), 12$ experts $(28.57 \%)$, and 5 researchers $(11.90 \%)$ related to revitalization of mountain villages. The length of service was $15.24( \pm 10.04)$ years for public officers, $11.58( \pm 8.97)$ years for experts, and $16.8( \pm 9.98)$ years for researchers, and the average length of service was $14.38( \pm 9.69)$ years. Public officers accounted for most of the respondents, and researchers were in longest service. All three groups worked for more than 10 years (Table 2).

\section{Test of significance for policy projects in the forest sector}

As a result of conducting a t-test on importance and performance of policy projects in the forest sector among policy stakeholders, it was found that performance (3.54) was lower than importance (3.78) with statistical significance $(p<.001)$. The type that showed the highest importance was No. 18- 'creating forest-related jobs' (4.45), followed by No. 19- 'supporting community revitalization' (4.20) and

Table 2. Demographic characteristics of policy stakeholders

\begin{tabular}{ccccc}
\hline Category & $\mathrm{N}$ & Percentage & \multicolumn{2}{c}{ Tenure } \\
\cline { 4 - 5 } & & 59.52 & 15.24 & Mean \\
\hline Public officer & 25 & 28.57 & 11.58 & 10.04 \\
Expert & 12 & 11.90 & 16.80 & 8.97 \\
Researcher & 5 & 100 & 14.38 & 9.98 \\
Total & 42 & & 9.69 \\
\hline
\end{tabular}


Table 3. Paired t-test analysis of importance and performance

$(\mathrm{N}=42)$

\begin{tabular}{|c|c|c|c|c|c|}
\hline No. & Type & Importance (I) & Performance (P) & Gap (I-P) & $t$ value \\
\hline 1 & Supporting cultivation of professional forestry workers & 4.20 & 4.00 & 0.20 & $2.082^{*}$ \\
\hline 2 & Creating a production base for forest products & 4.18 & 3.93 & 0.25 & $2.360^{* *}$ \\
\hline 3 & Strengthening competitiveness in clean forest products & 4.00 & 3.78 & 0.23 & $2.040^{*}$ \\
\hline 4 & Local forestry cooperative activation project & 3.60 & 3.45 & 0.15 & 1.183 \\
\hline 5 & Baekdudaegan resident support project & 3.48 & 3.55 & -0.07 & -0.621 \\
\hline 6 & Nurturing the wood industry & 3.58 & 3.28 & 0.30 & $2.149^{*}$ \\
\hline 7 & Creating forests for environmental improvement & 3.90 & 3.53 & 0.38 & $2.733^{* *}$ \\
\hline 8 & Creating green areas in living spaces & 3.78 & 3.58 & 0.20 & 1.347 \\
\hline 9 & Creating and managing street trees & 3.50 & 3.30 & 0.20 & 1.749 \\
\hline 10 & Creating dulle-gil (trails) & 3.78 & 3.58 & 0.20 & $2.082^{*}$ \\
\hline 11 & Spreading and industrializing garden culture & 3.55 & 3.38 & 0.18 & 1.481 \\
\hline 12 & Creating nice hiking trails & 3.88 & 3.70 & 0.18 & 1.639 \\
\hline 13 & Creating and operating forest recreation facilities & 4.15 & 3.95 & 0.20 & 1.599 \\
\hline 14 & Boosting forest leisure and sports & 3.68 & 3.58 & 0.10 & 0.850 \\
\hline 15 & Strengthening the base for forest education & 3.83 & 3.60 & 0.23 & $2.040^{*}$ \\
\hline 16 & Providing forest therapy service & 4.05 & 3.78 & 0.28 & $2.317^{*}$ \\
\hline 17 & Creating timber culture experience centers & 3.48 & 3.30 & 0.18 & 1.740 \\
\hline 18 & Creating forest-related jobs & 4.45 & 4.10 & 0.35 & $2.563^{*}$ \\
\hline 19 & Supporting community revitalization & 4.20 & 3.83 & 0.38 & $2.199^{*}$ \\
\hline 20 & Establishing and boosting forest tourism & 3.88 & 3.58 & 0.30 & $2.149^{*}$ \\
\hline 21 & Income-based mountain village housing project & 3.73 & 3.40 & 0.33 & $2.481^{*}$ \\
\hline 22 & Creating the base for development of the stone industry & 2.85 & 2.65 & 0.20 & 1.951 \\
\hline 23 & Establishing an integrated joint mountain monitoring system & 3.43 & 3.08 & 0.35 & $2.563^{*}$ \\
\hline 24 & Urban-rural exchange & 3.98 & 3.63 & 0.35 & $2.403^{*}$ \\
\hline 25 & Discovering forest cultural assets & 3.85 & 3.45 & 0.40 & $2.449^{*}$ \\
\hline 26 & Developing forest cultural assets into tourism resources & 3.93 & 3.68 & 0.25 & 1.818 \\
\hline 27 & Holding forest expositions or fairs, etc. & 3.28 & 2.95 & 0.33 & $2.061^{*}$ \\
\hline \multicolumn{2}{|r|}{ Total } & 3.78 & 3.54 & 0.24 & $12.524^{* * *}$ \\
\hline
\end{tabular}

No. 1- 'supporting cultivation of professional forestry workers' (4.20). The type that showed the highest performance was No. 18- 'creating forest-related jobs' (4.10), followed by No. 1- 'supporting cultivation of professional forestry workers' (4.00) and No. 13- 'creating and operating forest recreation facilities' (3.95). No. 1 and No. 18 were the same among the types with high importance and the types with high performance. As a result of conducting a t-test by type, 16 out of 27 types showed a significant difference $(p<.001)$. The 16 types were No. 1, 2, 3, 6, 7, 10, 15,
$16,18,19,20,21,23,24,25$, and 27 (Table 3). The 16 policy projects with significant difference show lower performance compared to importance, which is because the ongoing projects are not carried out for the purpose of revitalizing mountain villages. There was no difference at the level of statistical significance, but only No. 5'Baekdudaegan resident support project' showed higher performance than importance, which implies that direct support projects will be of greater help than indirect support projects for actual revitalization of mountain villages. 


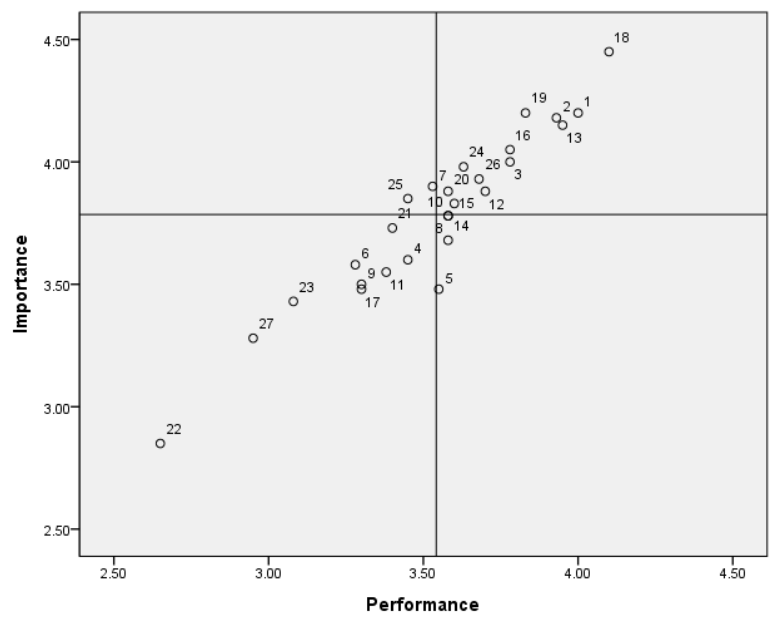

Fig. 3. IPA of project types in forest policy.

\section{Priorities and needs analysis}

\section{IPA (Importance-Performance Analysis)}

The IPA results according to the importance and performance of policy projects in the forest sector are as follows (Fig. 3). The types in KU (Quadrant 1) that show both high importance and performance were No. 1, 2, 3, $12,13,15,16,18,19,20,24$, and 26. The types in $\mathrm{CH}$ (Quadrant 2) with high importance but low performance were No. 7 and No. 25. In LP (Quadrant 3) with both low importance and performance, there were No. 4, 6, 9, $11,17,21,22,23$, and 27. In PO (Quadrant 4) with low importance but high performance, there were No. 5, 8, 10, and 14. Fig. 3 shows that the types of policy projects are concentrated in KU (Quadrant 1) and LP (Quadrant 3), which shows the limitations of IPA that fails to independently assess importance and performance.

\section{LF (Locus for Focus) model analysis}

The results of the LF model analysis through the difference between importance and performance of policy projects in the forest sector are as follows (Fig. 4). In $\mathrm{HH}$ (Quadrant 1) with high importance and a huge gap between importance and performance, there were No. 2, 7, 16, 18, 19, 20, 24, 25, and 26. The types in HL (Quadrant 2) with low importance and a huge gap between importance and performance were No. 6, 21, 23, and 27. The types in LL (Quadrant 3) with low importance and a small gap between importance and performance were No. 4, 5, 8, 9, 10, 11,

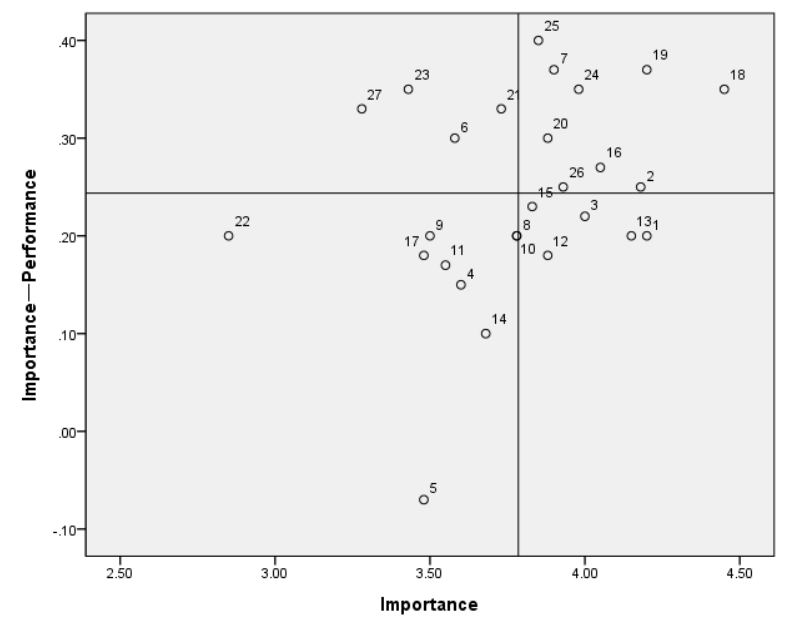

Fig. 4. Analysis of LF model in project types in forest policy.

14, 17, and 22. In LH (Quadrant 4) that shows high importance and a small gap between importance and performance, there were No. 1, 3, 12, 13, and 15 .

\section{Borich needs assessment}

The top priorities were those (9 types) in $\mathrm{HH}$ from the LF model among the priorities based on Borich needs assessment. As a result, No. 19- 'supporting community revitalization to enhance competency of mountain villages' showed the highest needs, followed by No. 18- 'creating forest-related jobs', No. 25- 'discovering forest cultural assets', No. 7- 'creating functional forests for environmental improvement', No. 24- 'urban-rural exchange', No. 21'income-based mountain village housing project', No. 23'establishing a joint monitoring system for rational conservation of mountain land', No. 20- 'establishing and boosting mountain tourism', and No. 16- 'providing forest therapy service' (Table 4).

\section{Results of comprehensive priority analysis}

We comprehensively analyzed IPA, LF model, and Borich needs assessment to identify the priorities of the types of policy projects in the forest sector that affect mountain village promotion (Table 5). The types with high comprehensive priorities were those in Quadrant 1 and Quadrant 2 in the IPA and LF model analysis, and those within the top 9 in Borich needs assessment.

The 9 types with high comprehensive priorities were No. 
Table 4. Analysis of Borich assessment model in project types in forest policy

\begin{tabular}{|c|c|c|c|c|c|c|c|c|}
\hline No. & Needs & Priority & No. & Needs & Priority & No. & Needs & Priority \\
\hline 1 & 0.840 & 16 & 10 & 0.755 & 18 & 19 & 1.575 & $1^{*}$ \\
\hline 2 & 1.044 & 12 & 11 & 0.621 & 22 & 20 & 1.163 & $8^{*}$ \\
\hline 3 & 0.900 & 14 & 12 & 0.678 & 21 & 21 & 1.211 & $6^{*}$ \\
\hline 4 & 0.540 & 25 & 13 & 0.830 & 17 & 22 & 0.570 & 24 \\
\hline 5 & -0.261 & 27 & 14 & 0.367 & 26 & 23 & 1.199 & $7^{*}$ \\
\hline 6 & 1.073 & 10 & 15 & 0.861 & 15 & 24 & 1.391 & $5^{*}$ \\
\hline 7 & 1.463 & $4^{*}$ & 16 & 1.114 & $9^{*}$ & 25 & 1.540 & $3^{*}$ \\
\hline 8 & 0.755 & 18 & 17 & 0.608 & 23 & 26 & 0.981 & 13 \\
\hline 9 & 0.700 & 20 & 18 & 1.558 & $2 *$ & 27 & 1.064 & 11 \\
\hline
\end{tabular}

${ }^{*}$ High priority.

Table 5. Result of comprehensive priority analysis for project types in forest policy

\begin{tabular}{|c|c|c|c|c|c|}
\hline No. & Type & $\begin{array}{c}\text { IPA } \\
\text { quadrant }\end{array}$ & $\begin{array}{l}\text { LF model } \\
\text { quadrant }\end{array}$ & $\begin{array}{l}\text { Borich needs } \\
\text { assessment }\end{array}$ & $\begin{array}{c}\text { Comprehensive } \\
\text { priority }\end{array}$ \\
\hline 1 & Supporting cultivation of professional forestry workers & $1(\mathrm{KU})$ & $4(\mathrm{LH})$ & 16 & - \\
\hline 2 & Creating a production base for forest products & $1(\mathrm{KU})$ & $1(\mathrm{HH})$ & 12 & - \\
\hline 3 & Strengthening competitiveness in clean forest products & $1(\mathrm{KU})$ & $4(\mathrm{LH})$ & 14 & - \\
\hline 4 & Local forestry cooperative activation project & $3(\mathrm{LP})$ & $3(\mathrm{LL})$ & 25 & $\nabla$ \\
\hline 5 & Baekdudaegan resident support project & $4(\mathrm{PO})$ & $3(\mathrm{LL})$ & 27 & - \\
\hline 6 & Nurturing the wood industry & $3(\mathrm{LP})$ & $2(\mathrm{HL})$ & 10 & - \\
\hline 7 & Creating forests for environmental improvement & $2(\mathrm{CH})$ & $1(\mathrm{HH})$ & 4 & (C) \\
\hline 8 & Creating green areas in living spaces & 4 (PO) & $3(\mathrm{LL})$ & 18 & - \\
\hline 9 & Creating and managing street trees & $3(\mathrm{LP})$ & $3(\mathrm{LL})$ & 20 & $\nabla$ \\
\hline 10 & Creating dulle-gil (trails) & $4(\mathrm{PO})$ & $3(\mathrm{LL})$ & 18 & - \\
\hline 11 & Spreading and industrializing garden culture & $3(\mathrm{LP})$ & $3(\mathrm{LL})$ & 22 & $\nabla$ \\
\hline 12 & Creating nice hiking trails & $1(\mathrm{KU})$ & $4(\mathrm{LH})$ & 21 & - \\
\hline 13 & Creating and operating forest recreation facilities & $1(\mathrm{KU})$ & $4(\mathrm{LH})$ & 17 & - \\
\hline 14 & Boosting forest leisure and sports & 4 (PO) & $3(\mathrm{LL})$ & 26 & - \\
\hline 15 & Strengthening the base for forest education & $1(\mathrm{KU})$ & $4(\mathrm{LH})$ & 15 & - \\
\hline 16 & Providing forest therapy service & $1(\mathrm{KU})$ & $1(\mathrm{HH})$ & 9 & ○ \\
\hline 17 & Creating timber culture experience centers & $3(\mathrm{LP})$ & $3(\mathrm{LL})$ & 23 & $\nabla$ \\
\hline 18 & Creating forest-related jobs & $1(\mathrm{KU})$ & $1(\mathrm{HH})$ & 2 & $\bigcirc$ \\
\hline 19 & Supporting community revitalization & $1(\mathrm{KU})$ & $1(\mathrm{HH})$ & 1 & $\bigcirc$ \\
\hline 20 & Establishing and boosting forest tourism & $1(\mathrm{KU})$ & $1(\mathrm{HH})$ & 8 & $\bigcirc$ \\
\hline 21 & Income-based mountain village housing project & $3(\mathrm{LP})$ & $2(\mathrm{HL})$ & 6 & - \\
\hline 22 & Creating the base for development of the stone industry & 3 (LP) & $3(\mathrm{LL})$ & 24 & $\nabla$ \\
\hline 23 & Establishing an integrated joint mountain monitoring system & $3(\mathrm{LP})$ & $2(\mathrm{HL})$ & 7 & - \\
\hline 24 & Urban-rural exchange & $1(\mathrm{KU})$ & $1(\mathrm{HH})$ & 5 & $\bigcirc$ \\
\hline 25 & Discovering forest cultural assets & $2(\mathrm{CH})$ & $1(\mathrm{HH})$ & 3 & (a) \\
\hline 26 & Developing forest cultural assets into tourism resources & $1(\mathrm{KU})$ & $1(\mathrm{HH})$ & 13 & - \\
\hline 27 & Holding forest expositions or fairs, etc. & $3(\mathrm{LP})$ & $2(\mathrm{HL})$ & 11 & - \\
\hline
\end{tabular}

(○) Top priority, $\bigcirc$ : Comprehensive priority, $\nabla$ : Low priority.

7- 'creating forests for environmental improvement', No. forest-related jobs', No. 19- 'supporting community revital16- 'providing forest therapy service', No. 18- 'creating ization', No. 20- 'establishing and boosting forest tourism', 
No. 24- 'urban-rural exchange', and No. 25- 'discovering forest cultural assets'. The types with the highest priorities were No. 7- 'creating forests for environmental improvement' and No. 25- 'discovering forest cultural assets', which were in CH (Quadrant 2) of IPA and HH (Quadrant 1) of the LF model.

There were 5 types with low comprehensive priorities, such as No. 4- 'local forestry cooperative activation project', No. 9- 'creating and managing street trees', No. 11'spreading and industrializing garden culture', No. 17'creating timber culture experience centers', and No. 22'creating the base for development of the stone industry'.

\section{Conclusion}

This study categorized the policy projects in the forest sector by 8 upper-level local governments into 27 types by surveying 42 policy stakeholders and examined the comprehensive priorities of the policy projects based on importance and performance. We used a paired t-test, IPA, LF model, and Borich needs assessment for comprehensive priority analysis, and the comprehensive priorities were derived by comparing the results. As a result of the t-test, there was a significant difference between importance and performance in 16 out of 27 types. CH (Quadrant 2) with high priorities in IPA included 'creating forests for environmental improvement' and 'discovering forest cultural assets'. In the LF model, HH (Quadrant 1) with high priorities included 'creating a production base for forest products', 'creating forests for environmental improvement', 'providing forest therapy service', 'creating forest-related jobs', 'supporting community revitalization', 'establishing and boosting forest tourism', 'urban-rural exchange', 'discovering forest cultural assets', and 'developing forest cultural assets into tourism resources'. Borich needs assessment showed high priorities in 'supporting community revitalization', 'creating forest-related jobs', 'discovering forest cultural assets', 'creating forests for environmental improvement', 'urban-rural exchange', 'income-based mountain village housing project', 'establishing an integrated mountain management system', 'establishing and boosting mountain tourism', and 'providing forest therapy service'. As a result of analyzing compre- hensive priorities by comparing IPA, LF model, and Borich needs assessment, the types with high comprehensive priorities were 'creating forests for environmental improvement', 'providing forest therapy service', 'creating forest-related jobs', 'supporting community revitalization', 'establishing and boosting forest tourism', 'urban-rural exchange', and 'discovering forest cultural assets'. Among them, the types with highest priorities were 'creating forests for environmental improvement' and 'discovering forest cultural assets'. The following conclusions can be drawn based on these results.

First, policy projects in the forest sector for mountain village promotion varied in terms of importance and performance. 'Supporting community revitalization' showed high importance, and 'creating and operating forest recreation facilities' showed high performance. 'Creating forest-related jobs' and 'supporting cultivation of professional forestry workers' showed both high importance and performance, implying that they would show an effect in mountain village promotion through policy implementation. Moreover, direct support projects with a clear purpose like 'Baekdudaegan resident support project' showed high performance, suggesting that these projects would have an affect on actual revitalization of mountain villages.

Second, the 7 types of policy projects with high comprehensive priorities were 'creating forests for environmental improvement', 'discovering forest cultural assets', 'establishing and boosting forest tourism', 'providing forest therapy service', 'creating forest-related jobs', 'supporting community revitalization', and 'urban-rural exchange'. These types require concentration in terms of improvement and smooth implementation for mountain village promotion. These results were similar to previous studies on mountain villages. Kang and Kim (2021) revealed that urban residents perceived environment, culture/leisure, health, income, and community as important in mountain village life, which is related to the policy projects with comprehensive priorities in this study. Moreover, Kwak et al. (2010) discovered that there was insufficient regional characteristics in mountain villages, which is a problem of exchange between cities and mountain villages, thereby raising the need for 'discovering forest cultural assets'. A study on ecotourism in mountain villages showed that visitors of mountain 
villages had a positive perception on ecotourism, proving that 'establishing and boosting forest tourism' is valid (Kim and Kim, 2018). Kim and Seo (2014) examined the factors affecting the decision to move to farming or rural villages and discovered that ecological community life was second-most important, which is consistent with the result of 'supporting community revitalization'. The results consistent with previous studies prove that the policy projects with comprehensive priorities in this study meet the general perception on mountain villages.

The types with highest priorities among the 7 types of policy projects were 'creating forests for environmental improvement' and 'discovering forest cultural assets'. Improving the physical environment and developing and operating contents are the projects that must be preferentially carried out for mountain village promotion. This is in line with the national policy trend such as the Korean Green New Deal and balanced national development. 'Creating forests for environmental improvement'reflects the global interest in the environment as a policy project that is in line with the green transformation of the city, space, and life infrastructure in the Korean Green New Deal that supports urban forest formation and smart green cities. Moreover, 'discovering forest cultural assets'is one of the most necessary types in line with the 'Distinctive culture and tourism using local assets', that is the sub-strategy of the 4th Five-year Plan for Balanced National Development. This shows that policy stakeholders are capturing the trend of national policies, which is reflected on the results of this study. Therefore, the method of comprehensive priority analysis in this study can be a useful tool in selecting policy projects.

Third, as a result of analyzing the difference depending on application of the analysis method, there were types with clearly different priorities. 'Supporting cultivation of professional forestry workers' and 'income-based mountain village housing project' showed different priorities depending on the application of the analysis method. This showed that policy priorities may vary depending on the analytical tool applied in policy establishment, which implies that a comprehensive review process must be included by applying various analysis methods in order to increase policy effectiveness.
In summary, this study came up with policy projects that are expected to have effect in mountain village promotion by assessing the importance and performance of 27 policy projects and discovered types of policy projects that require concentration in improvement and implementation based on comprehensive priority analysis. These results reflect previous studies and national policies, proving that the selected types of policy projects are suitable for mountain village promotion. As such, analyzing the priorities based on comprehensive analysis of policy projects in terms of improvement and implementation may increase policy effectiveness. However, this study has limitations in failing to comparatively analyze the survey results by group, such as public officers, experts, and researchers. Furthermore, it failed to select detailed priorities for each type of policy project in comprehensive priority analysis. Future studies must comparatively analyze policy projects in the agricultural administration sector and the forest sector as an important means to deal with local extinction and come up with significant results for balanced national development.

\section{References}

Borich, G.D. 1980. A needs assessment model for conducting follow-up studies. J. Teach. Educ. 31(3):39-42. https:/ doi.org/10.1177/002248718003100310

Byun, S.Y., H.I. Hwang, and K.H. Lee. 2019. Research on the childcare center directors report on the 2 nd mid and long-term child-care plan. J. Korea Open Assoc. Early Child. Educ. 24(2):391-413. https://doi.org/10.20437/ KOAECE24-2-16

Chae, C.J., K.H. Kim, and S.Y. Kang. 2021. Limiting ship accidents by identifying their causes and determining barriers to application of preventive measures. J. Mar. Sci. Eng. 9(3):302. https://doi.org/10.3390/jmse9030302

Cho, D.Y. 2009. Exploring how to set priority in need analysis with survey. J. Res. Educ. 35(8):165-187.

Deng, W. 2007. Using a revised importance-performance analysis approach: The case of Taiwanese hot springs tourism. Tour. Manag. 28(5):1274-1284. https://doi.org/10.1016/j.tourman.2006.07.010 
Ha, J.M. and D.H. Park. 2021. Educational needs related to elder abuse among undergraduate nursing students in Korea: An importance-performance analysis. Nurse Educ. Today. 104:104975. https://doi.org/10.1016/j.nedt. 2021.104975

Kang, B.H. and S.H. Kim. 2021. An analysis of the importance and Influence factors of urban residents on mountain village life. J. Korean Inst. For. Recreat. 25(2): 27-37. https://doi.org/10.34272/forest.2021.25.2.003

Kang, J.H., S.M. Lee, and K.L. Kim. 2021. Analysis of teachers needs on major factors for quality management of competency-based curriculum in higher education. J. Yeolin Educ. 29(1):51-69. https://doi.org/10.18230/tjye. 2021.29.1.51

Kim, S.H. and J.W. Seo. 2014. An analysis of settlement motivation and life satisfaction of return farmers on mountain village. J. Korean Soc. Rural Plan. 20(1): 105-113. https://doi.org/10.7851/ksrp.2014.20.1.105

Kim, Y.J. and J.H. Kim. 2018. A survey on recognition and requirements of mountain village visitors about the introduction of mountain eco-tourism. J. Korean Soc. For. Sci. 107(2):218-228. https://doi.org/10.14578/jkfs. 2018.107.2.218

Kwak, K.H., J.W. Seo, and K.W. An. 2010. Perception to exchange for urban and mountain village in the local government of Korea. J. Korean Inst. For. Recreat. $14(4): 17-26$.

Korea Forest Service (KFS). 2020. Statistical Yearbook of Forestry. Daejeon, Korea: KFS. Retrieved from https:// www.forest.go.kr.

Lee, C.M., J.Y. Chung, and M.S. Yang. 2020. An analysis of learner education needs for the operation and contents of liberal arts curriculum. Korean J. General Edu. 14(5): 109-121. https://doi.org/10.46392/kjge.2020.14.5.109

Lee, K.R. and D.Y. Jung. 2021. Examination of the educational needs of home visit nurses: A cross-sectional descriptive study. Int. J. Environ. Res. Public Health. 18(5):2319. https://doi.org/10.3390/ijerph18052319

Martilla, J.A. and J.C. James. 1977. Importance-performance analysis. J. Mark. 41(1):77-79. https://doi.org/10. 1177/002224297704100112

Mink, O.G., J.M. Shultz, and B.P. Mink. 1991. Developing and anaging Open Organizations: A Model and Method for Maximizing Organizational Potential. Austin, TX,
USA: Somerset Consulting Group, Inc.

National Institute of Forest Science (NIFoS). 2019. Forestoutlook. Seoul, Korea: NIFoS. Retrieved from http://know.nifos.go.kr/book/search/DetailView.ax?\&ci $\mathrm{d}=171999$

National Institute of Forest Science (NIFoS). 2020. Forestoutlook. Seoul, Korea: NIFoS. Retrieved from http://know.nifos.go.kr/book/search/DetailView.ax?\&ci $\mathrm{d}=173734$

National Institute of Forest Science (NIFoS). 2021a. A study on managing the settlement environment of mountain villages and revitalizing the village. Seoul, Korea: NIFoS. Retrieved from https://nifos.forest.go.kr.

National Institute of Forest Science (NIFoS). 2021b. Development of measures to foster mountain village base areas and revitalize operations. Seoul, Korea: NIFoS. Retrieved from https://nifos.forest.go.kr.

Oh, H.M. 2001. Revisiting importance-performance analysis. Tour. Manag. 22(6):617-627. https://doi.org/10.1016/S0261 $-5177(01) 00036-\mathrm{X}$

Oh, S.K., J.S. Jun, and Y.H. Park. 2014. Complementing a typical educational needs analysis using a survey in setting the priority of the needs. J. Res. Educ. 53(4): 77-98.

Park, K.G. 2017. Implications and evaluation of resident satisfaction degree on rural village development project: The case study of Hongcheon county. J. Korean Policy Stud. 17(4):101-123.

Park, Y.S. and H.R. Lee. 2016. The educational needs assessment of pre-service early childhood teachers on core competencies by grade level. J. Korea Open Assoc. Early Child. Educ. 21(1):343-366. https://doi.org/10. 20437/KOAECE21-1-14

Seo, H.S. and J.H. Hwang. 2019. Analyzing policy priorities for environment-friendly agriculture using AHP and IPA. Korean J. Agric. Manag. Policy 46(3):444469. https://doi.org/10.30805/KJAMP.2019.46.3.444

Seo, J.Y., S.J. Park, S.W. Park, and M.J. Rah. 2016. An analysis of competency for LEAs (Local Education Agencies) administrative officer: Focused on the importance-performance analysis (IPA). Korean J. Educ. Adm. 34(3):159-180.

So, S.C., C.S. Lee, and H.S. Han. 2019. The empirical 
study on 'the local decentralization policy' by IPA (Importance and performance analysis). Korea Local Adm. Rev. 33(1):119-144. https://doi.org/10.22783/krila. 2019.33.1.119

Yang, E.H. and J.S. Chung. 2010. Needs analysis for improving teaching competency. J. Edu. Technol. 26(2):
25-52. https://doi.org/10.17232/KSET.26.2.25

Yang, S.J., D.H. Shin, and Y.S. Song. 2015. An analysis of educational needs on self-leadership competencies of college students: A case study of $\mathrm{H}$ college. Korean J. Hum. Resour. Dev. Q. 17(2):241-266. https://doi.org/ 10.18211/kjhrdq.2015.17.2.009 